\title{
THROMBOSIS OF THE MAIN PULMONARY ARTERIES*
}

\author{
BY \\ OSCAR MAGIDSON AND GEORGE JACOBSON
}

\begin{abstract}
From the Department of Medicine, General Infirmary, Leeds, and the Departments of Medicine (Cardiology) and Radiology, Los Angeles County Hospital and University of Southern California
\end{abstract}

Received May 22, 1954

The clinical and pathological features of massive thrombosis of the pulmonary arteries have been well documented in recent years but the condition has seldom been recognized during life. In many cases clinical diagnosis is unlikely because the thrombosis is terminal or insidious, in patients already seriously ill with cardiac or pulmonary disease, and merely hastens the end by increasing the load on the right ventricle. However, thrombus may be present in the main pulmonary arteries for a period of weeks or even years, until sudden fresh thrombosis completes the occlusion and proves fatal, so that the condition cannot be considered purely terminal (Brenner, 1935; and Savacool and Charr, 1941). Furthermore, a number of reports have demonstrated that thrombosis of main pulmonary arteries may, on rare occasions, initiate chronic right heart failure, closely resembling chronic cor pulmonale from the more usual causes. Von Jürgensen (1908) described a case showing complete obstruction of the pulmonary trunk with " mainly old firm clot"; he stated that a large portion of the lumen could be " rendered impermeable" without causing death. Experimentally this suggestion was confirmed by the demonstration in dogs that the main pulmonary artery could be compressed gradually until 60 per cent of its lumen was obliterated, without a fall in systemic blood pressure, and that death did not occur until roughly 90 per cent occlusion was reached (Gibbon et al., 1932).

Posselt (1909) could find only three examples of complete occlusion of the main pulmonary artery or its branches. Ljungdahl (1928), Barnes and Yater (1929), Jump and Baumann (1929) and Means and Mallory (1932) described patients showing chronic right heart failure; in each case organized or organizing thrombus occluded the main pulmonary artery or its branches. The case of Means and Mallory showed evidence of collateral circulation to the lungs via hypertrophied bronchial and other mediastinal arteries. Brenner (1935) demonstrated the relative frequency of thrombosis of smaller arteries, but he could only report six examples of organized thrombus of the main pulmonary artery; involvement of primary branches was commoner, but in either situation symptoms attributable to the occlusion were rare. Fowler (1934), Mallory (1940), and Covey (1943) described patients showing a chronic course, characterized by dyspnœa, cyanosis, præcordial distress, and heart failure. In each of these patients severe paroxysmal cough sometimes associated with deepening cyanosis was a noteworthy feature. Harvey and Hogg (1946) discussed the condition in children, citing fourteen reported cases and adding one of their own. Carrol (1950) presented five new cases in two of which venous catheterization of the heart revealed elevated right ventricular pressures. In one patient thoracotomy was undertaken after a diagnosis of obstruction of the left pulmonary artery had been made and a biopsy of the artery revealed organized thrombosis. This author emphasized again the occurrence of chronic right heart failure and noted the frequent finding of right ventricular hypertrophy patterns in the electrocardiogram. Hanelin and Eyler

\footnotetext{
* Part of this work was done while one of us (O. M.) was a Fellow in Medicine (Cardiology) of the University of Southern California, supported by the San Diego Heart Association.
} 
(1951) presented five patients and established the criteria on which a radiological diagnosis might be made.

It is the purpose of this paper to determine the incidence of the condition and to present and comment upon the clinical and pathological features of nine examples.

Present Material and Classification. Nine patients were studied of whom six were seen in Los Angeles and three in Leeds. The patients have been separated on clinical grounds into a group of four showing chronic right heart failure (Group I) and a second group of five with an acute or subacute course (Group II).

Incidence. The incidence of the condition over a twenty-year period (1930-1949) was determined from a study of the extensive autopsy records of the Los Angeles County Hospital. The results are shown in Table I which also includes the figures for frank pulmonary embolism for comparison. Evidently the condition under discussion is quite rare, occurring approximately once in five thousand autopsies in a large general hospital.

TABLE I

InCidence of Pulmonary Embolism and Arterial Thrombosis

\begin{tabular}{lll|c|c|c|c}
\hline & & $\begin{array}{c}\text { Total autopsies } \\
1930-39\end{array}$ & $\begin{array}{c}\text { Pulmonary artery } \\
\text { thrombosis } \\
\text { (all size arteries) }\end{array}$ & $\begin{array}{c}\text { Thrombosis of major } \\
\text { pulmonary arteries } \\
\text { as cause of death }\end{array}$ & Pulmonary embolism \\
\hline Total.. &.. &.. & 35,003 & 361 & 7 & 1469 \\
Percentage &.. &.. & 100 & 1.03 & 0.02 & 4.2 \\
\hline
\end{tabular}

\section{Group I. Patients with Chronic Right Heart Failure}

Case 1. B. W. was a widow, aged 59 years, at the time of her death. In March, 1949, she was admitted to hospital with an appendix abscess which resolved without surgical intervention. At that time the cardiovascular system was clinically normal. In June, 1949, she suffered an attack of thrombophlebitis of the left leg. During the course of this attack she noticed the onset of shortness of breath on effort. In February, 1950, the right leg became swollen and tender and the dyspnoea increased in severity. She was found to have a right femoral thrombosis. There was no cardiac enlargement, but a soft apical systolic murmur and a blood pressure (B.P.) of $180 / 110 \mathrm{~mm}$. In September, 1950, she was admitted to hospital as an urgent case with severe breathlessness, orthopnœa, and painless swelling of the legs.

She was orthopnœic with cyanosis of the lips and fingers, but without finger clubbing. The venous pressure was raised with a strong auricular systolic wave in the external jugular veins. The pulse rate was 100 a minute and regular. B.P. $160 / 110 \mathrm{~mm}$. Hg. There was gross œedema of the legs and a sacral pad and the liver was enlarged and tender. The heart was clinically enlarged with a parasternal heave and a pulmonary diastolic shock. There was a systolic thrill maximal over the sternal end of the third left rib. The second sound in the pulmonary area (PII) was markedly accentuated and split and a loud systolic murmur was audible, loudest in the third left intercostal space.

An electrocardiogram showed right ventricular hypertrophy. The skiagram showed cardiac enlargement with fullness of the pulmonary artery segment. The lung fields were relatively clear (Fig. 1).

She responded moderately well to treatment for her heart failure and was discharged in November, free of odema, able to walk 100 yds. but still cyanotic. Her condition remained relatively stationary until February, 1951, when she had an attack of " influenza " shortly after which she was re-admitted to hospital with severe breathlessness, cyanosis, and œdema. The clinical findings were as before. Progress was very slow but after slight improvement, dyspnœa and cyanosis suddenly increased and she died within the next few minutes.

Post-mortem Examination. Heart. The right ventricle was hypertrophied and dilated. Left ventricle appeared normal. Coronary arteries showed minimal atheroma. There was no congenital nor acquired valvular disease.

Pulmonary Arteries. Organized antemortem thrombus straddled the bifurcation of the main pulmonary artery, extending $3 \mathrm{~cm}$. into the right branch and along the whole length of the left into the hilum of the lung. The clot extended several centimetres down into the main trunk. Overall the clot occluded about three- 
quarters of the lumen of the vessels (Fig. 3 and 4). The lungs showed no gross abnormalities. In the peripheral venous system the right femoral and popliteal system contained organized and fresh thrombus.

Histology. The pulmonary artery clot consisted of old thrombus firmly attached to the walls of the arteries and showing dense organization in its deeper layers.

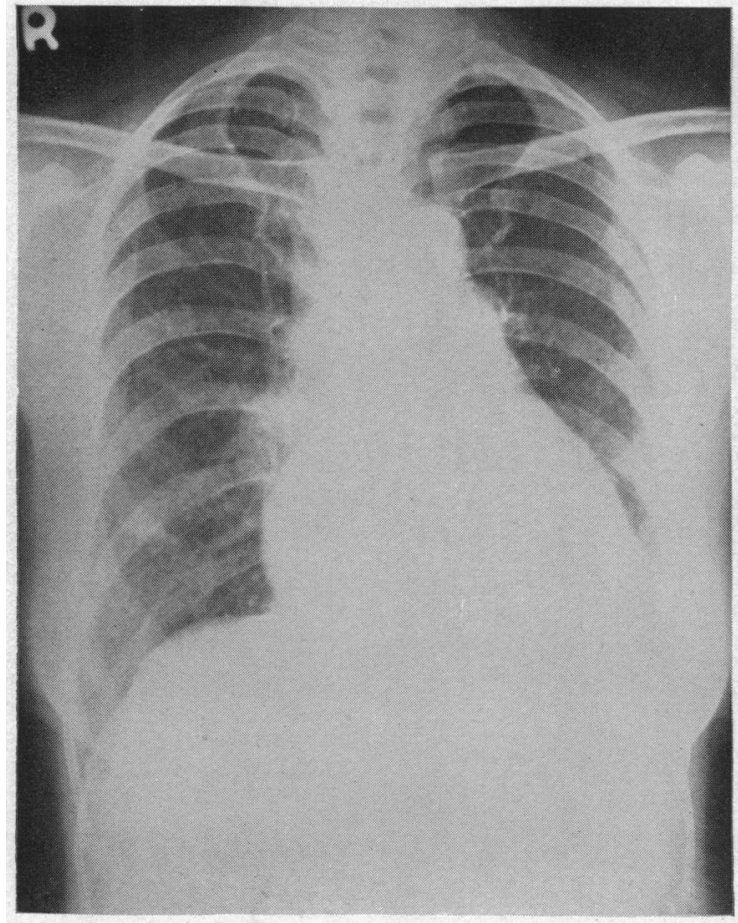

Fig. 1:-Case 1. Skiagram of September, 1950.

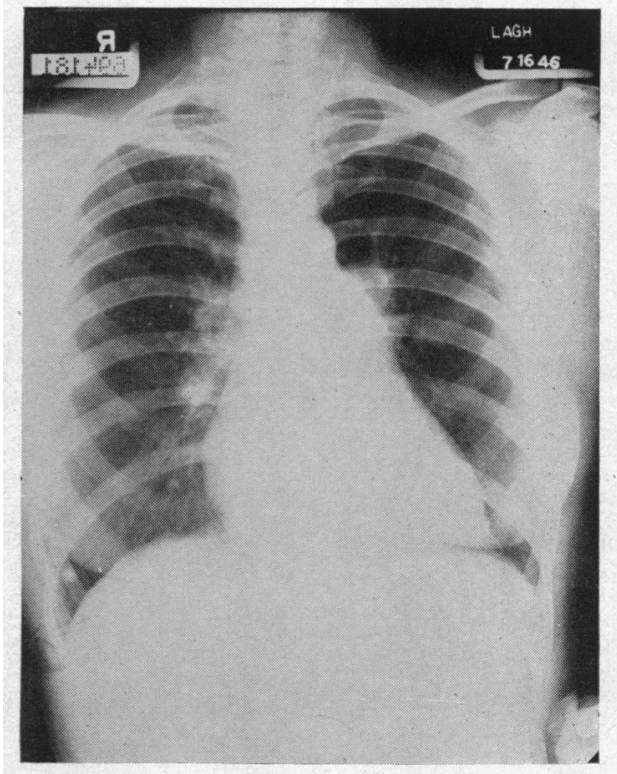

Fig. 2.-Case 2. Skiagram of July, 1946. The shadow adjacent to the pulmonary artery segment was suspected to be a pulmonary neoplasm.

Comment. At the time of this patient's admission to hospital with heart failure her previous history and physical findings were not known and she was thought to be suffering from congenital heart disease, either a ventricular or atrial septal defect. The right-sided enlargement of the heart, thrill, and split second sound were in keeping with either diagnosis. The final clinical diagnosis was ventricular septal defect with associated pulmonary hypertension.

Necropsy revealed only massive organized thrombus of the major pulmonary arteries without evidence of underlying disease. There is no evidence that the thrombosis was secondary to primary pulmonary vascular sclerosis and clinical signs of pulmonary hypertension were not present in February, 1950, yet in September, 1950, she was in severe right heart failure. It seems likely that the illness started early in 1950 and that the thrombus propagated rapidly prior to her admission in September. Severe heart failure from obstruction lasted in all six months. Despite the absence of a clear history we believe that the attack of thrombophlebitis in 1949 was responsible for pulmonary embolism which was followed by extension of thrombus and increasing obstruction of the main pulmonary arteries.

Case 2. E. M. B. was a woman, aged 48 years at the time of her death. She first attended as an outpatient in June, 1946, with severe non-productive cough, dyspnœa, pain in the left thigh and calf and in the right side of the chest. There was cedema of both legs especially in the left leg, which was cyanosed with dilated superficial veins. The heart was not enlarged but PII was loud and a pulmonary systolic murmur was audible. It was noted at this time that she became quite dyspnoic with the effort of combing her hair. She was admitted to the wards and with rest her condition improved. A skiagram taken at this time is shown in Fig. 2. An electrocardiogram showed right ventricular hypertrophy. One month later she was re-admitted with cough, breathlessness, and a return of swelling of the left leg and thigh with associated tenderness and thickening of the femoral vein. The arm-to-tongue circulation time 


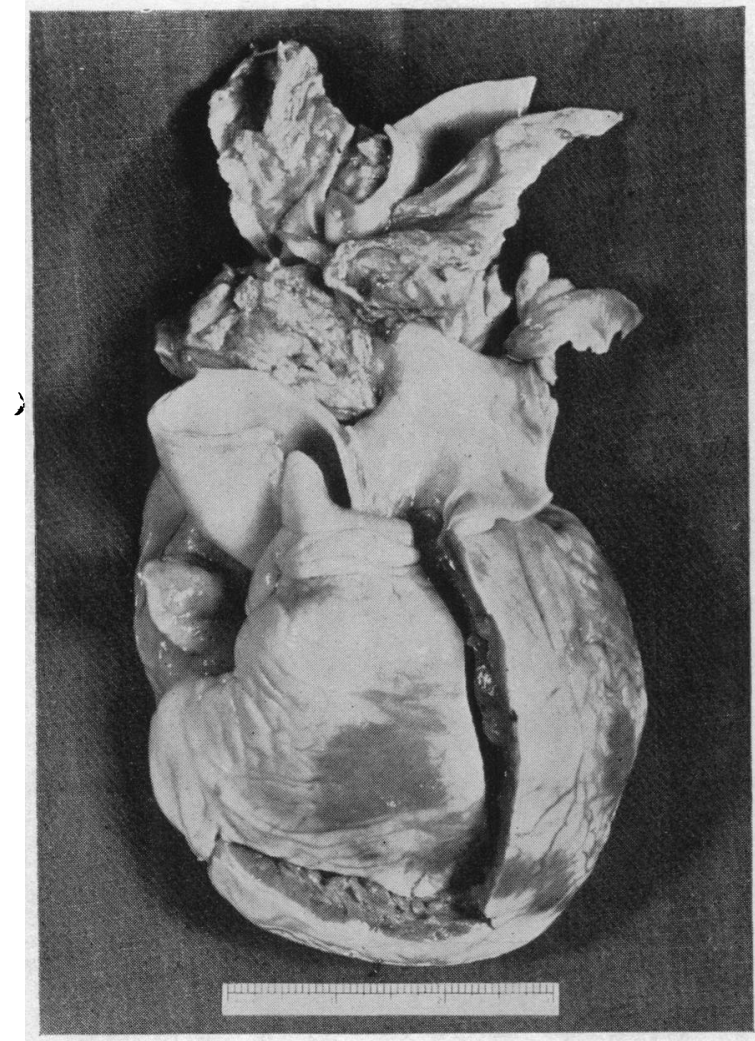

FIG. 3.-Case 1. Heart showing right ventricular hypertrophy and a thrombus in the pulmonary arteries.



FIG. 4.-Case 1. Lung root showing a dense thrombus occluding the pulmonary artery.

was prolonged to $28 \mathrm{sec}$. and the venous pressure was markedly raised. The blood pressure was $150 / 80 \mathrm{~mm}$. She was discharged improved within a few weeks. She was admitted for the third time in November, 1947. She presented a picture of right heart failure with high venous pressure, cyanosis, and a loud systolic murmur and thrill over the body of the heart. It was considered that she might have a ventricular septal defect and pulmonary hypertension. A skiagram at this time showed an apparent mass in the region of the left pulmonary artery and a diagnosis of neoplasm of the lung was considered. In early December she had evidence of consolidation in the left upper lobe with a slight fever; in late December she experienced acute right pleuritic pain and a friction rub was heard over the right lung base. With each of these two incidents cyanosis increased considerably. In January, 1948, cardiac catheterization was attempted but demonstrated only a raised right atrial pressure. She was discharged only to be readmitted for the last time in April, 1948. The symptoms were as before but in addition she had constant dull boring substernal pain from which no relief could be obtained. She was feeling very weak and dizzy and the œdema of the legs had become extreme.

Physical examination showed her to be markedly orthopnœic, distressed, and cyanotic. There was distension and vigorous systolic pulsation of the deep veins of the neck. Grade II finger clubbing was present. The pulse was regular at 46 a minute. The blood pressure was $105 / 70 \mathrm{~mm}$. The heart was enlarged. A changing first heart sound suggested complete heart block. A rough systolic murmur was heard over the body and base of the heart and was accompanied by a thrill. The liver was enlarged and tender. There were no râles or crepitations in the lungs. The skin was cold and clammy and she died suddenly on the evening of the day of admission.

Post-mortem Examination. Heart. Greatly enlarged with dilatation of the right chambers. Weight $480 \mathrm{~g}$. Left ventricular wall $10-12 \mathrm{~mm}$. thick. Right ventricular wall $8-9 \mathrm{~mm}$. thick. Coronary arteries thin-walled and patent. There was a patent foramen ovale which could be opened up to a diameter of about $2 \cdot 5 \mathrm{~mm}$.

Pulmonary arteries. Firmly adherent dense thrombus was found beginning just below the bifurcation of the pulmonary artery and especially attached to the right main branch which was completely occluded. 
The clot extended into the branches to all three lobes. Some of the vessels distal to the thrombus were still patent although numerous small branches showed dense firm fibrous strands in their lumina consistent with old organized thrombi; a few of these vessels had been recanalized. The left lung was similarly affected with the exception that the main artery on the left was partially patent.

Lungs. Generally, the lung parenchyma, tracheobronchial tree, and lymph nodes showed nothing of note with the exception of a dense scar in the left lower lobe extending to the pleural surface.

Peripheral veins. The left femoral system contained old organized thrombus.

Histology. The pleura and lung showed scattered atypical tubercles of sarcoidosis. Sections of mediastinal lymph nodes showed the characteristic changes of Boeck's sarcoid. The larger pulmonary vessels showed evidence of both old organized thrombus and relatively recent clot.

Comment. This woman had an illness of two-years duration with four admissions to hospital. The cause of her severe symptoms and heart failure was not suspected. It seems probable that she suffered from occlusion of the pulmonary vessels dating from pulmonary embolism occurring during the course of thrombophlebitis or phlebothrombosis in June, 1946. The extensive clot found at autopsy must have resulted from propagation of thrombus around the original embolus. The patent foramen ovale was only $2.5 \mathrm{~mm}$. in diameter and flap-like and could not be classed as an atrial septal defect. It is likely that part of the venous return may have passed from right to left through the foramen ovale in the face of the pulmonary arterial obstruction.

It may be postulated that the thrombus arose in situ in lungs affected by sarcoidosis but the scattered and relatively slight involvement and the history makes this less likely than that the condition was secondary to pulmonary embolism.

Case 3. N. L. H. was a woman, aged 60 years at the time of her death. She was well until 1942 when she had a hysterectomy for fibroids. Two weeks after the operation she suffered sudden onset of severe retrosternal pain radiating into the right arm associated with breathlessness. She was told she had had a heart attack and was kept in bed for eight weeks. Since that time she had been breathless, severely on exertion and slightly even at rest. Positive Wassermann and Kahn reactions were noted in 1942, and in 1944 she had a course of intramuscular injections. In 1946 her doctor prescribed digitalis because of severe breathlessness and swelling of the ankles. She was admitted to hospital in April, 1947, because of digitalis intoxication. At this time she was dyspnœic and slightly cyanotic, but free of œdema. There was venous hypertension, moderate cardiac enlargement, gallop rhythm, and accentuation of PII. The blood pressure was $150 / 90 \mathrm{~mm}$. A cardiogram showed right axis deviation and clockwise rotation. A skiagram showed cardiac enlargement with a density at the right base. The Wassermann and Kahn reactions were positive.

After her discharge from hospital she remained virtually bedridden. A skiagram taken in February, 1948, is shown in Fig. 5. She was finally admitted in September, 1948. She was extremely ill and cyanotic with slight finger clubbing, cardiac enlargement, gallop rhythm, and an accentuated pulmonary second sound. There were no murmurs. An electrocardiogram showed bigeminy due to auricular premature beats and right ventricular enlargement. She lapsed into coma and died within a few days of admission.

Post-mortem Examination. Heart. Weight $450 \mathrm{~g}$. The right heart was enlarged and dilated. The right ventricle measured $12 \mathrm{~mm}$. in thickness and the left ventricle $13 \mathrm{~mm}$. The cardiac valves and coronary arteries appeared healthy.

Pulmonary arteries. Contained within the main pulmonary artery was an organized thrombus approximately $3 \mathrm{~cm}$. in diameter which extended upwards and completely occluded the left pulmonary artery extending into its primary branches (Fig. 6). The pulmonary vascular tree throughout both lungs appeared dilated and degenerative changes were present throughout.

Lungs. The right lung showed multiple ante-mortem clots throughout the entire arterial tree. The right upper lobe appeared to be completely infarcted. Two small infarcts were present in the right lower lobe.

Histology. Main pulmonary artery. The intima was covered by densely organized thrombus. The media and adventitia showed much scarring and moderately heavy round cell infiltration. There was marked fibrosis with round cell and plasma cell infiltration in the perivascular spaces. The changes were suggestive but not diagnostic of a syphilitic origin.

Arterioles showed fibrous thickening and in places round cell infiltration. The small pulmonary arteries were severely involved by arteriosclerotic changes. The aorta showed slight scarring in the perivascular spaces of the media and much arteriosclerosis of the intima.

Comment. This woman suffered from chronic right heart failure and at death showed densely organized thrombotic occlusion of the main and left pulmonary arteries. She was a known syphilitic and the pathological changes within the pulmonary vessels were suggestive of syphilis. It seems likely that the heart failure resulted from the pulmonary vascular sclerosis complicated by thrombosis in situ. Six years before death, however, she suffered an episode suggesting pulmonary embolism. It is possible that the thrombus originated from the pulmonary embolus and was not a true autochthonous thrombus. 


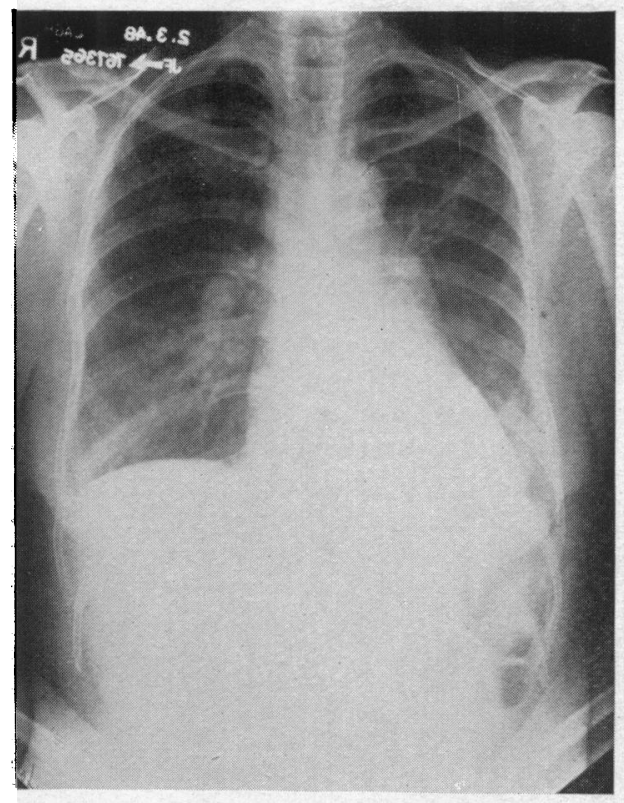

FIG. 5.-Case 5. Skiagram of May, 1948.

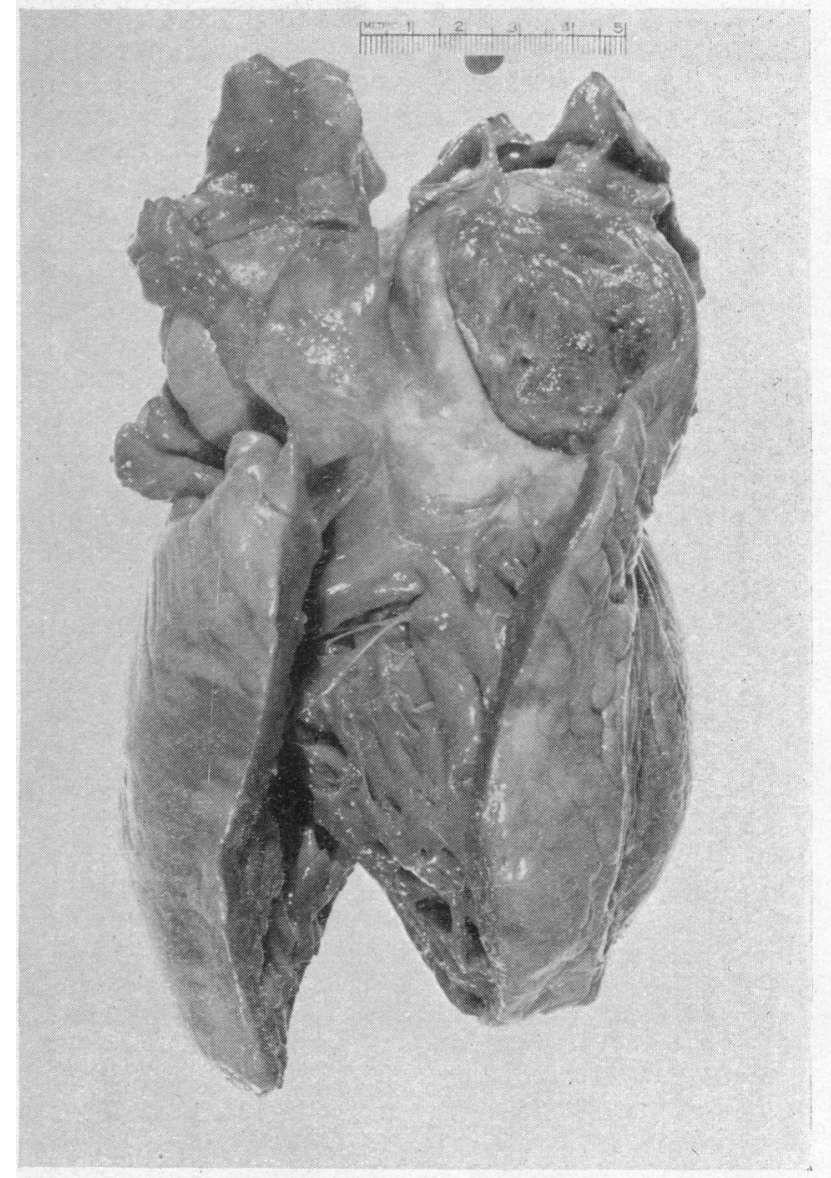

FIG. 6.-Case 3. Heart and pulmonary artery showing a massive pulmonary artery thrombus.

Case 4. B. G. was a man, aged 40 at the time of his death. He was first admitted to hospital in September, 1947. Several months before he had had left-sided pneumonia. Since that time he had experienced early morning cough and breathlessness on exertion. A systolic murmur over the cardiac base, enlargement of the heart with a prominent pulmonary artery segment, and right axis deviation in the cardiogram led to a diagnosis of congenital pulmonary stenosis. In 1948 and 1949 he was seen in the out-patient clinic; breathlessness was troublesome and for a period in 1949 he had œdema of the legs and spent three months in bed at home. In 1950 the diagnosis was considered to rest between atrial septal defect and primary pulmonary hypertension. He was re-admitted in January, 1953. He was well built without cyanosis or finger clubbing. The pulse was regular, and the blood pressure $95 / 80 \mathrm{~mm}$. in both arms. The neck veins were distended and noted to be pulsating vigorously. The heart was enlarged and the only auscultatory sign of note was a very loud and split PII. The liver was enlarged and slight œedema was present. While in hospital he had an attack of severe epigastric pain lasting fourteen hours, and on another occasion left pleuritic pain. He was discharged in April still incapacitated by dyspnœea on the slightest exertion. He re-entered hospital for the last time in November, 1953, with severe congestive heart failure and pain across the lower chest and epigastrium. He was now cyanotic, orthopnœic, and in severe right heart failure with gallop rhythm. The cardiogram showed right ventricular enlargement. Skiagrams taken at this time are shown in Fig. 7 and 8. He died within a few days of admission with intractable heart failure.

Post-mortem Examination. Heart. Weight $700 \mathrm{~g}$. There was enormous enlargement due to massive hypertrophy of the right atrium and ventricle. There was no evidence of any congenital anomaly.

Pulmonary arteries. The first $3 \mathrm{~cm}$. of the pulmonary trunk appeared practically normal though somewhat dilated. Distal to this point the trunk and both pulmonary arteries were enormously distended by laminated thrombus of some age, which was firmly adherent to three-quarters of the lumen and organized in 


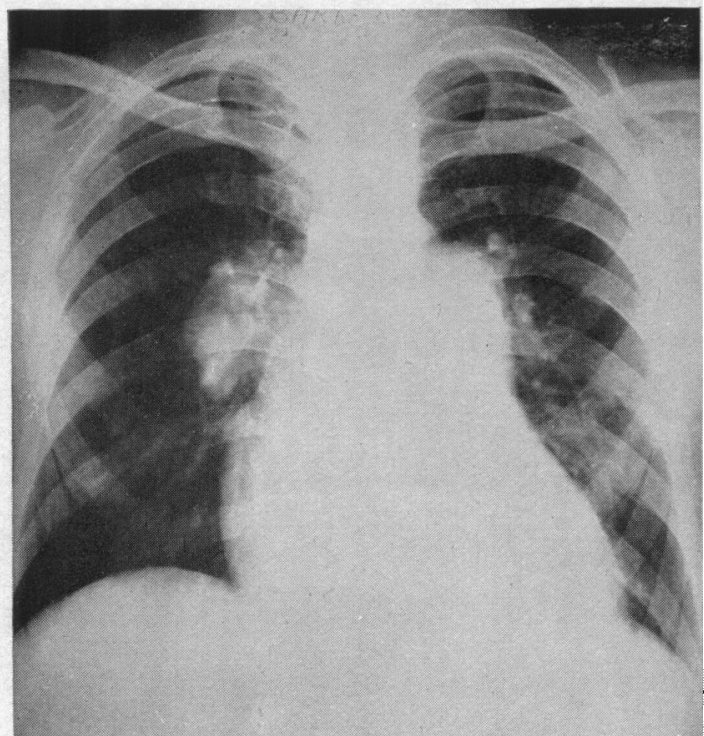

Fig. 7.-Case 4. Skiagram of November, 1953.

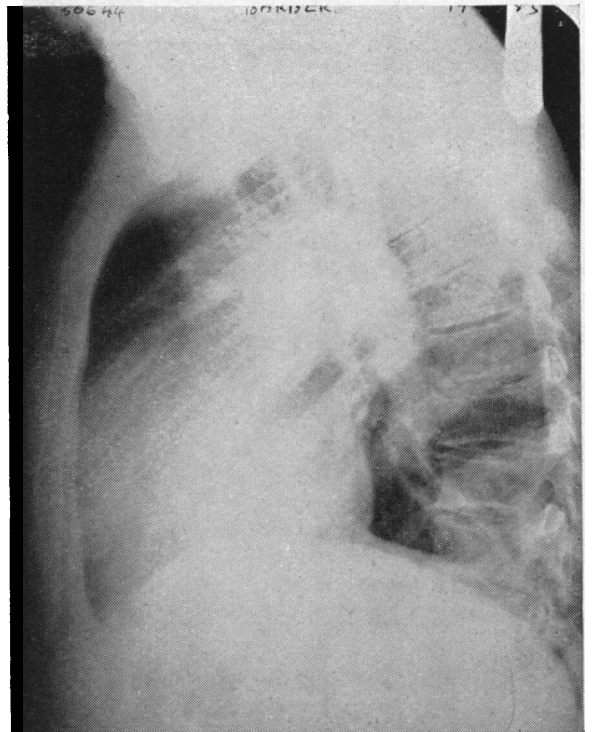

FIG. 8.-Case 4. Left lateral skiagram of November, 1953, demonstrating the dense left pulmonary artery with an irregular end.

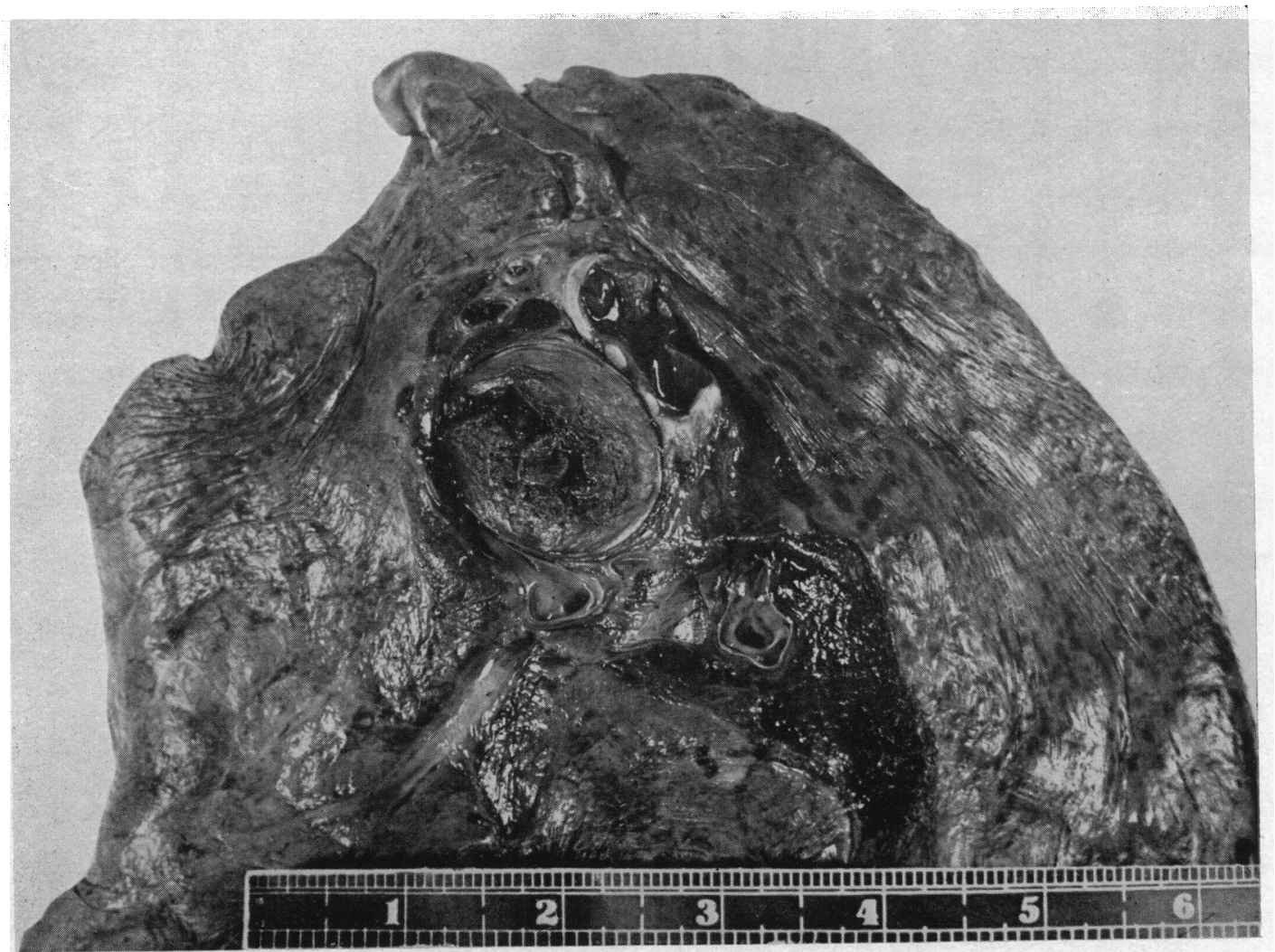

Fig. 9.-Case 4. Lung root showing the pulmonary artery occluded and distended with firm thrombus. 
its deeper layers. The thrombus extended for some distance into the branches of the pulmonary arteries in both lungs. There was only a small cleft between the thrombus and the wall of the pulmonary trunk (Fig. 9). The lungs showed several small, fairly recent infarcts in all lobes of both lungs. There was no evidence of pulmonary disease. The leg veins were free of thrombus.

Histology. The majority of the arterioles examined showed concentric medial hypertrophy and narrowing of their lumina. In a few the thickened muscle coat was also partially fibrotic. There was also thickening and condensation of the adventitia. In most of the vessels so affected the lumen was concentrically narrowed and in some obliterated; occasionally the lumen was irregular due to the protrusion of small pads or nodules of muscular tissue from the media.

Comment. This man had progressive right heart failure which lasted about six years. The disproportionate enlargement of the right side of the heart and the absence of any congenital cardiac anomaly indicated that the heart failure was due to obstruction of the pulmonary circulation. Histological examination showed the primary condition to be one of sclerosis of the pulmonary vessels, complicated at a later stage by obliterating thrombosis of the trunk and larger branches of the pulmonary artery.

\section{Group II. Patients with Acute and Subacute Failure}

Case 5. T. A. M. was a man, aged 78 years. He was admitted to hospital in 1949 as an emergency. For several months he had had severe breathlessness on effort which had become extremely acute two days before admission. He presented acute dyspnœa accompanied by moderate cyanosis and restlessness. His skin was cold and dry. There was much venous distension. The heart rate was 130 . There was cardiac enlargement and a gallop rhythm. The blood pressure was $110 / 70 \mathrm{~mm}$. He made no response to treatment and died within six hours of admission.

Post-mortem Examination. Heart. Weight $370 \mathrm{~g}$. Moderate right ventricular hypertrophy and dilatation. The right ventricular wall measured 6-8 $\mathrm{mm}$. and the left $12-14 \mathrm{~mm}$.

Pulmonary arteries. The main vessel was moderately dilated and measured $10 \mathrm{~cm}$. in circumference. At the bifurcation there was a relatively recent thrombus, reddish with scattered white lines in it, extending $10 \mathrm{~cm}$. into the left pulmonary artery. It was moderately adherent to underlying, old, well-laminated, brownish-white thrombus densely adherent to the pulmonary artery at the bifurcation. Old thrombus extended about $5 \mathrm{~cm}$. into the left pulmonary artery and approximately $4 \mathrm{~cm}$. into the right. The combined clot occluded approximately one-half of the lumen of the right and left pulmonary arteries. The lungs showed no emphysema or gross disease.

Peripheral veins. Old thrombus was present in the deep femoral system on the right side.

Histology. The pulmonary artery wall was thicker than normal and densely adherent to it was the thrombus, showing advanced organization; attached to this was recent thrombus showing lines of Zahn. The smaller arteries and arterioles showed no pathological changes.

Comment. Death in this patient occurred from acute obstruction of the pulmonary circulation due to the deposition of recent clot upon old adherent thrombus. There was no clinical indication of the cause of the initial thrombosis and the autopsy revealed no pulmonary or cardiac disease.

Case 6. W. B. M. was a 52-year-old coloured man who entered hospital for increasing dyspnœa over the preceding three weeks. He had suffered from breathlessness on effort for about three years. Three hours before admission he experienced pain in the left shoulder. Examination showed moderate dyspnœa and orthopnœa. No definite abnormality could be made out in the lungs or heart but the blood pressure was $235 / 130 \mathrm{~mm}$. A few hours after entering he developed pain in the abdomen with sweating and pallor and died after passing a bloody stool.

Post-mortem Examination. Heart. Weight $500 \mathrm{~g}$. Both the right and left ventricular walls measured about $12 \mathrm{~mm}$. in thickness. Coronary arteries were patent and showed very little atheroma. The pulmonary arteries generally appeared thickened and showed moderate atheroma. An old well organized thrombus markedly adherent to the vessel wall arose $2 \mathrm{~cm}$. proximal to the bifurcation of the main pulmonary artery. It filled the major portion of the lumen of both the main branches. The thrombus on the right measured 2-3 cm. in diameter, the remaining lumen forming a small crescent about one-half this size. On the left about one-half of the lumen was occluded. Overlying the deeper organized clot was more recent thrombus. The lungs were equal in size and crepitant.

Case 7. W. F. C. was a man admitted to hospital at the age of 41 years with dyspnoa and hæmoptosis. A cavity was found at the apex of the left lower lobe but tubercle bacilli were not isolated. Breathlessness continued and he was re-admitted six months later with a severe exacerbation of the dyspnœa, tightness in the chest, and abdominal pain which had been present for two weeks.

He was dyspnœic and cyanotic with a cold moist skin. There was tachycardia, cardiac enlargement and a triple rhythm at the apex. The lungs showed scanty crepitations at the bases. The blood pressure was unobtainable and the venous pressure measured $320 \mathrm{~mm}$. water in a brachial vein. He died shortly after admission. 
Post-mortem Examination. Heart. Weight $450 \mathrm{~g}$. The right ventricular wall measured $8 \mathrm{~mm}$., the left ventricular wall $14 \mathrm{~mm}$. in thickness. The myocardium and valves appeared normal. The coronary arteries showed minimal atheroma.

Pulmonary arteries. The main pulmonary artery was occluded by a red thrombus beginning $2 \mathrm{~cm}$. beyond the valve and extending out as far as the smaller branches in both lungs. Superficially the thrombus was red and soft and showed typical laminæ, but deeper it was tough, yellow and adherent to the arterial wall. The wall of the main pulmonary a tery was not noticeably thickened but in most of the secondary branches were thickened yellowish atheromatous plaques. The lungs were light and fluffy. The apex of the left lower lobe contained a cystic cavity measuring $3 \mathrm{~cm}$. in diameter.

Peripheral veins. The left common iliac vein was obstructed by a tough fibrous plug.

Case 8. J. W. K. entered hospital with a provisional diagnosis of cerebral embolism from rheumatic heart disease. His relatives reported that he had been breathless and had complained of pressure in his chest and swelling of his ankles for about four weeks. The day before admission he had become drowsy and then rapidly comatose.

He was a 55-year-old man, comatose and cyanotic, with ankle œdema. Distension of neck and arm veins was evident. There was a loudly accentuated PII. He became more cyanotic and died within a few hours of admission.

Post-mortem Examination. Hzart. Weight $670 \mathrm{~g}$. The right ventricular wall measured $7 \mathrm{~mm}$. in thickness and the left $14 \mathrm{~mm}$. The valves showed only a slight and incomplete degree of adhesion of the aortic valve cusps. The coronary arteries were patent throughout.

Pulmonary arteries. In the pulmonary artery, beginning at the bifurcation, was a massive thrombus which was adherent and whose deeper layers were pale and organized. The lungs showed no gross abnormality. The brain and cerebral vessels showed no gross abnormality.

Histology. There were some hyaline changes in the pulmonary artery contiguous upon organized thrombus. Unorganized clot had been laid down on the surface. The smaller vessels showed no significant changes. The lung parenchyma was emphysematous.

Comment. As in Case 5, Cases 6, 7, and 8 showed extensive recent clot superimposed on deep organized thrombus. In each patient symptoms had progressed for several weeks, finally necessitating admission to hospital in extremis. The clinical picture on admission in Cases 5 and 7 closely resembled that seen in massive pulmonary embolism. None of the cases had a history suggesting embolism in the past and no obvious cause for the original thrombosis or its preterminal extension could be found.

Case 9. M. H. was a woman, aged 74 years, who lived alone and who was found ill in bed by a neighbour. She had been in bed for three weeks with weakness, breathlessness, and blueness and pain in the tip of the nose. On examination she was thin, dehydrated, and mentally disorientated. The neck veins were distended, the hands were cold, and the nose showed early gangrene. The heart was clinically enlarged. The blood pressure was unobtainable and the pulse impalpable. A sacral pad of œdema was present and the liver was enlarged. She died without a diagnosis having been made.

Post-mortem Examination. Heart. Weight $400 \mathrm{~g}$. Great dilatation of the right side. Mild coronary atheroma was present.

Pulmonary arteries. All the branches of the pulmonary arteries were filled with firm antemortem thrombus of some duration. The thrombus started at the commencement of the two main branches of the pulmonary trunk and extended to the periphery, filling all the visible branches. The lungs appeared small. There were bilateral, blood stained, pleural effusions.

The only other significant findings were a small chronic duodenal ulcer and cystitis.

Comment. This woman survived three weeks with propagating pulmonary artery thrombus which almost certainly arose in situ. Dehydration may have played an important part in initiating the thrombosis. The marked peripheral vaso-constriction leading to gangrene of the tip of the nose was a striking manifestation in this case.

\section{Clinical Features}

Group I. In Cases 1 and 2 the whole cardiac illness can reasonably be attributed to pulmonary artery thrombosis, while in Cases 3 and 4 right heart disease due to pulmonary vascular sclerosis. probably existed before the onset of the thrombosis. The clinical features were those of chronic and intractable right heart failure without evidence of pulmonary parenchymal disease or pulmonary congestion yet with severe breathlessness on slight effort and orthopnœa. Cough was a troublesome symptom in Cases 2 and 4 and in both severe retrosternal and epigastric pain occurred in the later stages of the illness. This latter symptom has been discussed by Middleton (1943). Cyanosis and 
finger clubbing were late developments. No direct evidence as to whether the cyanosis was central or peripheral was obtained, but a right-to-left shunt through the patent foramen ovale in Case 2, in which a raised right atrial pressure was demonstrated, seems probable.

Physical examination was characterized by a raised venous pressure, enlargement of the heart, triple rhythm, accentuation of the second sound in the pulmonary area, and basal systolic murmurs. In Cases 1 and 2 loud rough systolic murmurs accompanied by a thrill were noted, leading in both to the diagnosis of congenital heart disease. The occurrence of cardiac murmurs has been mentioned occasionally in relation to pulmonary artery thrombosis (Posselt, 1909; Covey, 1943; Carrol, 1950; and Dimond and Jones, 1953). The arterial blood pressure was well sustained until the terminal stages of the illness.

Electrocardiograms were taken at various stages of the illness and always showed right ventricular enlargement patterns. The P pulmonale was not a feature, being seen only in Case 4 in the right præcordial leads. Complete heart block was recorded terminally in Case 2; Case 3 showed bigeminy due to auricular premature beats during her last admission and Case 4 had a prolonged $\mathbf{P}-\mathrm{R}$ interval at least two years before his death.

Radiological examination was carried out in these cases and although the correct diagnosis was not considered during life, a review of the films showed that the features described by Hanelin and Eyler (1951) were present (Fig. 1, 4, 5, 7, and 8). These features are as follows.

(1) Enlargement of the right heart.

(2) Dilatation of the affected pulmonary artery proximal to the block.

(3) Enlargement and alteration in the contour of the vessels at the level of the thrombus.

(4) Decrease in the calibre of the vessels distal to the thrombus with increased radiotranslucency in the corresponding areas.

Group II. Cases 5, 6, and 7 were admitted with acute heart failure after a few weeks to a few months of increasing breathlessness on exertion. The clinical picture in Cases 5 and 7 closely resembled that seen in acute massive pulmonary embolism, with venous hypertension, gallop rhythm, tachycardia, cyanosis, and cold extremities. Case 8 had complained of increasing dyspnoa, chest oppression, and swelling of the ankles for about a month prior to admission and was admitted in coma. Case 9 followed a subacute course over a period of several weeks, characterized by severe peripheral circulatory insufficiency associated with cardiac failure culminating in early gangrene of the extremities.

\section{Pathological Features}

The essential pathological findings are set out in Table II. In all cases the main pulmonary trunk or the bifurcation was affected by the thrombosis with extension into one or other or both branches. No predeliction for one or other branch of the pulmonary artery was seen. In all the cases firm, old clot was found adherent to the main trunk or the bifurcation and in general more recent clot had been added. Case 9 differed somewhat in showing uniform continuous thrombus throughout the smaller and larger branches of the pulmonary artery. With the exception of this patient the pathological features were essentially similar in all cases irrespective of the clinical group into which the patients were placed.

Gross parenchymal disease of the lungs was not seen. Significant disease of the large pulmonary arteries was found in only three cases (Table II). Arteriolar disease, possibly syphilitic, was found in Case 3, and diffuse arteriolar sclerosis of unknown origin in Case 4. Valvular or arteriosclerotic heart disease was not present and only Case 6 with severe hypertension had heart disease that might have altered the clinical picture produced by obstruction in the pulmonary circulation. All the cases showed hypertrophy or dilatation of the right side of the heart consequent on the pulmonary vascular obstruction and could be considered, from a pathological standpoint, examples of chronic or subacute cor pulmonale.

A series of cases of this type raises the question whether pulmonary embolism with subsequent 
TABLE II

Pathological Findings

\begin{tabular}{|c|c|c|c|c|}
\hline Case No. & Age and sex & Pulmonary arteries & Heart & Other significant findings \\
\hline 1 & $59 \mathrm{~F}$ & $\begin{array}{l}\text { Organized thrombus main } \\
\text { and both branches oc- } \\
\text { cluded } 3 / 4 \text { lumen }\end{array}$ & $\begin{array}{l}420 \text { g. R.V. hypertrophy } \\
\text { and dilatation }\end{array}$ & $\begin{array}{l}\text { Organized and fresh thrombus } \\
\text { right femoral venous system }\end{array}$ \\
\hline 2 & $48 \mathrm{~F}$ & $\begin{array}{l}\text { Dense thrombus main and } \\
\text { both branches }\end{array}$ & $\begin{array}{l}480 \text { g. R.V. hypertrophy. } \\
\text { Patent foramen ovale }\end{array}$ & $\begin{array}{l}\text { Histologically Boecks sarcoid } \\
\text { of lung and tracheo bronchial } \\
\text { lymph nodes. Old throm- } \\
\text { bus, left femoral system }\end{array}$ \\
\hline 3 & $60 \mathrm{~F}$ & $\begin{array}{l}\text { Organized thrombus main } \\
\text { and completely occluding } \\
\text { left }\end{array}$ & $\begin{array}{l}450 \text { g. R. V. hypertrophy. } \\
\text { Mural thrombus right } \\
\text { ventricle }\end{array}$ & $\begin{array}{l}\text { Possibly syphilitic pulmonary } \\
\text { arteritis. Tuberculous cavity } \\
\text { left apex. Infarcts } L \text { and } R \\
\text { upper lobes }\end{array}$ \\
\hline 4 & $40 \mathrm{M}$ & $\begin{array}{l}\text { Trunk and both branches } \\
\text { distended with laminated } \\
\text { clot of some age }\end{array}$ & $\begin{array}{l}700 \text { g. Massive R.V. } \\
\text { hypertrophy }\end{array}$ & $\begin{array}{l}\text { Histologically primary pul- } \\
\text { monary vascular sclerosis }\end{array}$ \\
\hline 5 & $78 \mathrm{M}$ & $\begin{array}{l}\text { Old well-laminated clot ad- } \\
\text { herent to bifurcation. } \\
\text { Recent clot superimposed }\end{array}$ & $\begin{array}{l}370 \mathrm{~g} . \mathrm{R} . \mathrm{V} . \text { hypertrophy } \\
\text { and dilatation }\end{array}$ & $\begin{array}{l}\text { Old thrombus in right deep } \\
\text { femoral veins }\end{array}$ \\
\hline 6 & $52 \mathrm{M}$ & $\begin{array}{l}\text { Old thrombus main and } \\
\text { both branches }\end{array}$ & $\begin{array}{l}500 \mathrm{~g} . \\
\text { and dilatation }\end{array}$ & Pulmonary artery atheroma \\
\hline 7 & $41 \mathrm{M}$ & $\begin{array}{l}\text { Deep tough thrombus ad- } \\
\text { herent to wall main } \\
\text { branch. Superficial recent } \\
\text { clot }\end{array}$ & $450 \mathrm{~g}$. & $\begin{array}{l}\text { Tough fibrous plug in left com- } \\
\text { mon iliac vein. Atheroma } \\
\text { secondary branches pul- } \\
\text { monary artery }\end{array}$ \\
\hline 8 & $55 \mathrm{M}$ & Thrombus across bifurcation & $\begin{array}{l}670 \mathrm{~g} \text {. Slight adhesions } \\
\text { of aortic cusps }\end{array}$ & Nothing of note \\
\hline 9 & $74 \mathrm{~F}$ & $\begin{array}{l}\text { All branches on both sides } \\
\text { filled with firm ante- } \\
\text { mortem thrombus extend- } \\
\text { ing to bifurcation }\end{array}$ & $\begin{array}{l}400 \mathrm{~g} . \text { Marked dilatation } \\
\text { of right side }\end{array}$ & $\begin{array}{l}\text { Small chronic duodenal ulcer. } \\
\text { Early gangrene of nose. } \\
\text { Cystitis }\end{array}$ \\
\hline
\end{tabular}

addition and propagation of thrombus on the one hand or autochthonous thrombosis on the other is the important ætiological factor. When the characteristic features of pulmonary emboli are obscured by superadded thrombus their identification is rendered difficult or impossible (Belt, 1939) and a decision has to be made from the associated pathological findings such as the condition of the lungs and pulmonary vessels, evidence of a source of a embolus and the clinical course of the patient. There is little doubt that single or repeated pulmonary emboli may become organized, and with the subsequent addition of thrombus and the development of obstruction of the pulmonary circulation produce a clinical picture of chronic or subacute cor pulmonale (Ljungdahl, 1928; Means and Mallory, 1931; Belt, 1939; Hampton and Castleman, 1940; Carrol, 1950; and Hanelin and Eyler, 1951). Keating et al. (1953), however, while conceding the importance of antecedent embolism, could recognize the sequence of embolism followed by thrombosis in only one of their seven cases; they therefore stressed the importance of thrombosis in situ. The occurrence of autochthonous thrombosis has been well documented (Billings, 1921; Brenner, 1935; Savacool and Charr, 1941; and Bryson, 1949). The factors that are considered to predispose to thrombosis in situ are diffuse pulmonary disease such as tuberculosis, pneumokoniosis, or emphysema, diffuse pulmonary vascular disease, cardiac failure and pulmonary hypertension, dehydration, anoxæmia, and altered coagulability of the blood. The presence of one or more of these factors does not 
preclude the occurrence of pulmonary embolism but actually prediposes towards it by encouraging leg vein thrombosis and also predisposes to the spread of secondary thrombus upon a embolus. Apart from the widespread uniform thrombosis which is exemplified in Case 9 and seems undoubtedly to be autochthonous in origin, we are frequently left with a consideration of the history and an examination of the peripheral veins as the only basis on which to determine the origin of the thrombus.

In the present series there was good clinical evidence of embolism and lower limb phlebothrombosis in Cases 1 and 2, while Case 3 had an episode highly suggestive of embolism some six years before death. Case 4 had no episode suggesting embolism and the peripheral veins were free of thrombus. In Cases 5-8 an adequate past history was not available and the occurrence of pulmonary embolism could not be excluded. Thrombus was found in the leg veins in Cases 5 and 7 .

\section{Summary and Conclusions}

Massive thrombotic occlusion of the main pulmonary arteries is a rare condition occurring perhaps once in five thousand post-mortem examinations. As a syndrome of clinical significance it is probably even rarer. Occasionally it is responsible for a picture of chronic cor pulmonale and the occurrence of unusual murmurs and thrills may suggest the diagnosis of congenital heart disease. The condition should be considered in the differential diagnosis of pulmonary vascular obstruction and a prior history suggesting pulmonary embolism or infarction should lend support for the diagnosis. There appear to be no specific clinical features enabling the diagnosis to be made with confidence and the more acute cases may resemble massive pulmonary embolism. The radiological features are important in the diagnosis but may be difficult to interpret in the presence of underlying cardio-pulmonary disease. Four chronic and five subacute cases have been described and previous papers have been briefly reviewed. The importance of pulmonary embolism in initiating the thrombosis is stressed but a proportion of the cases are apparently the result of thrombosis in situ. It was not possible to determine whether pulmonary embolism had occurred in the past other than by inference based on a careful and full case history. Pathological examination of the present cases showed that old thrombus was attached to the main pulmonary artery or straddled the bifurcation and the addition of fresh thrombus had obliterated the pulmonary circulation and led to death.

We wish to thank the Staffs of the General Infirmary, Leeds, and of the Los Angeles County Hospital for permission to study cases under their care. Thanks are due to Dr. J. R. H. Towers for bringing Case 4 to our attention and to Dr. George C. Griffith and Dr. W. Goldie for advice and criticism.

\section{REFERENCES}

Barnes, A. R., and Yater, W. M. (1929). M. Clin. North America, 12, 1603.

Belt, T. H. (1939). Lancet, 2, 730.

Billings, F. T. (1921). Pennsylvania med. J., 25, 151.

Brenner, O. (1935). Arch. intern. Med., 56, 1189.

Bryson, W. J. (1949). Dis. Chest, 15, 366.

Carrol, D. (1950). Amer. J. Med., 9, 175.

Covey, G. W. (1943). Ann. intern. Med., 18, 851.

Dimond, E. G. and Jones, T. R. (1954). Amer. Heart J., 47, 105.

Fowler, W. M. (1934). Ann. intern. Med., 7, 1101.

Gibbon, G. H., Hopkinson, M., and Churchill, E. D. (1932). J. Clin. Invest., $11,534$.

Hampton, A. O., and Castleman, B. (1940), Amer. J. Roentgenol., 43, 305.

Hanelin, J., and Eyler, W. R. (1951). Radiology, 56, 689.

Harvey, E. B., and Hogg, P. (1946) Amer. J. Dis. Child., 71, 67.

Jump, H. D., and Baumann, F. (1929). Pennsylvania med. J., 32, 754.

Keating, A. R., Burkey, J. N., Hellerstein, H. K., and Feil, H. (1953). Amer. J. Roent., 69, 208.

Ljungdahl, M. (1928). Deutsches Arch. klin. Med., 160, 1.

Mallory, T. B. (1940). New Eng. J. Med., $222,457$.

Means, J. A., and Mallory, T. B. (1931). Ann. intern. Med., 5, 417.

Middleton, W. S. (1943). Ann. intern. Med., 18, 345.

Posselt, A. (1909). Ergebn. allg. Path. path. Anat., 13, 298.

Savacool, J. W., and Charr, R. (1941). Amer. Rev. Tuberc., 44, 42.

von Jürgensen, T. (1908). Diseases of the Heart, in Nothnagel's Practice. W. B. Saunders \& Company, Philadelphia. 